\title{
Anthropogenic pollutants on top soils along a section of the Salaria state road, central Italy
}

\author{
Alessandra Venuti ${ }^{1}$, Laura Alfonsi $i^{1,{ }^{\star}}$, Andrea Cavallo ${ }^{1,2}$ \\ ${ }^{1}$ Istituto Nazionale di Geofisica e Vulcanologia, Rome, Italy \\ ${ }^{2}$ Laboratorio Tecnologico di Grosseto, Borgo Santa Rita - Cinigiano (Grosseto), Italy
}

\author{
Article history \\ Received March 30, 2016; accepted July 27, 2016. \\ Subject classification: \\ Magnetic susceptibility, Environmental magnetism, Pollution, Soils.
}

\begin{abstract}
Magnetic susceptibility (MS) is employed among others magnetic parameters to investigate pollution along a high traffic density road. In this study, MS field survey and magnetic laboratory analyses were applied to five sites along the Via Salaria road in the northern districts of Rome. Scanning electron microscope and energy dispersive spectroscopy analyses have also been employed to reveal the nature of Fe rich particles of anthropogenic origin. In general, the soil samples revealed to contain low coercivity minerals (e.g., magnetite) with different grain size, Fe-oxides occurring in various forms (spherules, aggregates, octahedral crystals and angular particles) are typically found close to the road side border at some of the analyzed sites. Magnetic minerals concentration in proximity of the road border resulted higher at sites with higher traffic volume and, in general, decreases with the distance from it. Evidences of anthropogenic material in topsoils were found within the first $5 \mathrm{~m}$ from the road border. The study confirms that the in situ measurements of the magnetic susceptibility are a valuable tool to rapidly investigate variations in the magnetic susceptibility profile related to anthropogenic contribution.
\end{abstract}

\section{Introduction}

In the last decade numerous studies on anthropogenic pollution demonstrated a close relation among heavy metals and magnetic parameters in tree leaves or barks [e.g., Moreno et al. 2003, Gautam et al. 2004, Blaha and Appel 2005; Maher et al. 2008, Szönyi et al. 2008], urban dustfall [e.g., Muxworthy et al. 2001, Xia et al. 2008], and soils [e.g., Durza 1999, Petrovský et al. 2001, Hanesch and Scholger 2002, Lecoanet et al. 2003, Magiera et al. 2006, D’Emilio et al. 2007]. In particular several studies utilized the magnetic susceptibility field measurements as a rapid, low cost method to investigate the source and distribution of pollutants in soils along heavy traffic roads [Hoffman et al. 1999, Lu et al. 2011]. These studies remark an overall enhancement of the magnetic susceptibility field signal in the first few meters close to the roadside border [Gautam et al. 2004, Kim et al. 2009, Bućko et al. 2011]. Rock magnetic analysis on selected samples, pointed out a direct correlation among the susceptibility enhanced values and anthropogenic pollutants from automotive and industrial plants [Strzyszcz and Magiera 1998, Goddu et al. 2004, Marié et al. 2010]. These correlations generally apply when strict conditions characterize the analyzed area, i.e., unploughed terrains, flat soil surface, constant winds direction, and homogeneous soil parent material [Hoffmann et al. 1999], while the effect of soil properties and local conditions (i.e., prevalent winds directions, slope of the investigated area, weathering due to heavy rain) could clearly affect the final results [Kapička et al. 2001].

For the research development of this study we applied a pre-existent methodology to a sector of the Salaria state road (S.S. 4). The sites investigated differ for characteristics of the parental rock material and site local conditions. This local study applies the surficial magnetic susceptibility method as screening for anthropogenic magnetic pollutants in conditions where differences in local geology and morphology persist.

\section{Methods and materials}

The objects of the study are natural soils sampled at five localities which differ for the characteristic of the rock parental material outcropping nearby. Then, being the soils the result of the alteration of the parental rock, background lithology of the natural soils along the interstate Salaria road are not homogeneous (Figure 1). The extra urban sector of the Via Salaria state road is surveyed for surficial magnetic susceptibility with in situ measurements and discrete soil samples analysis, on the aim to characterize the origin of the magnetic fraction 


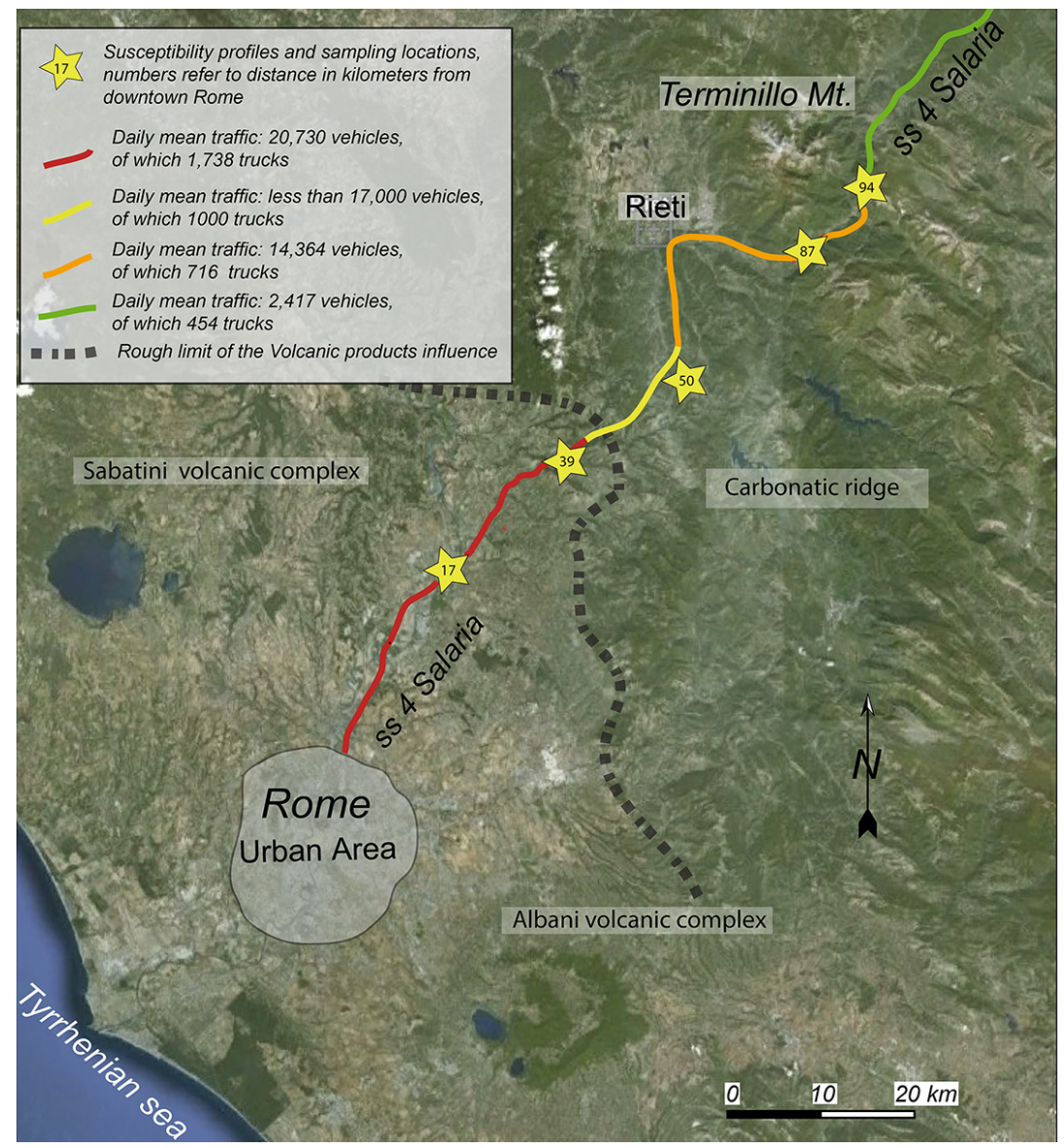

Figure 1. Location map of the study area, stars locate the sampling sites, symbols as in legend. Site denomination follows the kilometric distance from downtown Rome along the state Salaria road SS4.

content. Traffic volume, slope of the selected areas, and characters of the topsoils are not alike among the studied sites. The numbering of the sites refers to the kilometers along the Salaria road whose zero point is placed in downtown Rome (Figure 1).

The in situ magnetic susceptibility variations are recorded along profiles perpendicular to the road axis. Measurements have been taken on only one side of the road since the intense grade of urbanization made impossible to get cross-road surveying. Discrete samples have been collected for laboratory rock-magnetic and chemical analytical determination at given points along the profiles (positions of the discrete sampling are visible in the profile of Figure 2). In total, forty topsoil samples have been collected and analyzed. The topsoil at the sampling sites is constituted by: recent alluvial deposits at site SS17, SS87, and SS94; Pliocene-Pleistocene sand and clay at site SS39, and middle EoceneOligocene marl and clay marl at SS50. Additionally, close to sites SS39 and SS17 localized outcrops of pedogenised tufa are exposed [Carta Geologica d'Italia 1:100,000, Sheets 150, 144, and 139].

The profiles of the in situ low-field magnetic susceptibility $\left(\kappa \times 10^{-5} \mathrm{SI}\right)$ extended up to a maximum distance of $50 \mathrm{~m}$ off the road side, depending on local site conditions (Figure 2). The measurements were taken using a Bartington MS3 susceptibility meter System, equipped with D field loop sensor; measurements were performed every $0.5 \mathrm{~m}$ in the first $10 \mathrm{~m}$ of the profile, and then every $1 \mathrm{~m}$. Measurements at each site were repeated in different time and seasonal period, this to avoid any possible meteorological effects on the data. The discrete samples have been collected with standard cubic plastic containers of $8 \mathrm{~cm}^{3}$ along the profiles, and then dried at room temperature. The 40 samples were then analyzed in laboratory to determine the low field mass specific susceptibility $\left(\chi, \mathrm{m}^{3} / \mathrm{kg}\right.$, on AGICO Kappabridge system, KLY-2 model); a 2G Enterprises (model 755) with an in-line AF demagnetizer and DC field solenoid was used to impart an anhysteretic remanent magnetization (ARM) using a bias field of $0.05 \mathrm{mT}$ and a peak-alternating field (AF) of $100 \mathrm{mT}$. The magnetic intensity of the samples was then measured and stepwise demagnetized using AF peaks of 10, 20,30, and, $40 \mathrm{mT}$. Hysteresis properties, i.e., coercive force $\left(\mathrm{H}_{\mathrm{c}}\right)$, saturation magnetization $\left(\mathrm{M}_{\mathrm{s}}\right)$, and saturation remanent magnetization $\left(\mathrm{M}_{\mathrm{rs}}\right)$ were attained (MicroMag magnetometer, Princeton Measurements Corp. Model 2900 MicromagTM), with a maximum applied field of $1 \mathrm{~T}$. Coercivity of remanence $\left(\mathrm{H}_{\mathrm{cr}}\right)$ was derived from 

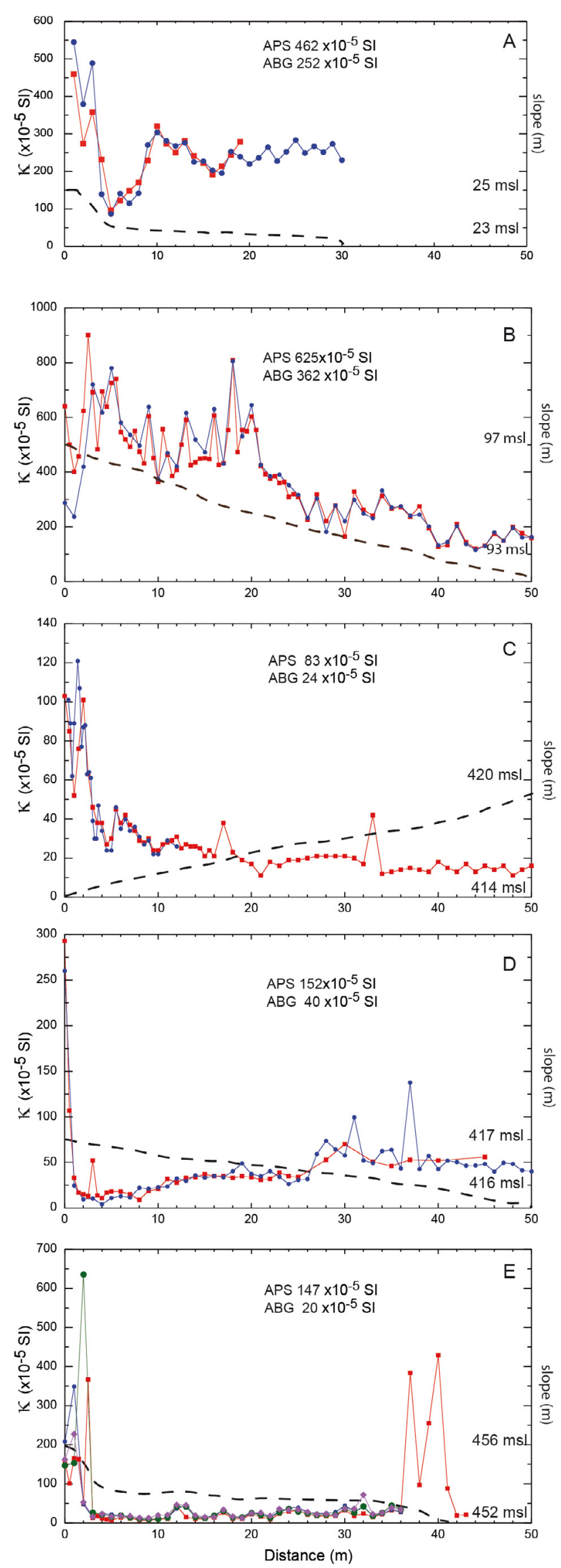

Figure 2. Magnetic susceptibility field profiles for sites SS17 (A), SS39 (B), SS50 (C), SS87 (D), and SS94 (E). Dashed dark line represents the trend of slope profile. APS: is the averaged peak magnetic susceptibility value; ABG: is the averaged magnetic susceptibility background value. backfield remagnetization curves. The magnetic standard parameters obtained are listed in Table 1. Thermoremanent susceptibility curves in the temperature range of $40-700^{\circ} \mathrm{C}$ in air, made on magnetic extracted samples (Nd-Fe-B-REE magnet, Rare Earth Element) were determined (MFK1-FA Kappabridge, coupled with a CS-3 high-temperature furnace apparatus).

Microscope observations, have been carried on selected soil samples to qualitatively characterize the chemical content and identify the morphological aspects of the magnetic fraction. For this set of analyses the samples were dried at room temperature, gently powdered and subject to magnetic extraction using a Nd-Fe-B-REE (Rare Earth Element) magnet housed in a plastic sheath. JEOL JSM 6500F Field Emission Scanning Electron Microscope (FESEM, resolution of 1.5 $\mathrm{nm}$ ), operating at $10 / 15 \mathrm{kV}$ equipped with detectors for $\mathrm{x}$-ray (EDS, with a resolution of $133 \mathrm{eV}$ ) was used to analyze the extracted material sparse on conductive dedicated tape. All the laboratory rock magnetic analyses and morphological study utilized the facilities present at the paleomagnetism and high pressure high temperature laboratories of the Istituto Nazionale di Geofisica e Vulcanologia (INGV, Rome).

\section{Rock magnetic analysis methods and results}

A total of 44 discrete soil samples were analyzed to characterize the magnetic content through rock magnetic specific analyses. The instruments utilized and the main results are detailed in the following sections.

\subsection{Magnetic susceptibility field profiles}

The overall view of the susceptibility in situ profiles defines a sharp magnetic susceptibility enhancement close to the road border at four out of the five studied sites, i.e., SS17, SS39, SS50, and SS94 (Figure 2AB-C and E). At SS94 an unexpected peak is observed also at circa $40 \mathrm{~m}$ off the road, caused by an undisclosed local source of magnetic susceptibility disturbances, as probably a residual of a camp fire (Figure $2 \mathrm{E}$ ). Instead, at site SS39 the magnetic susceptibility values show that the increased MS values are spread over wide portion of the profile, defining a broad area of MS enhancement (Figure 2B). The trend of the slope, dashed line in Figure 2B, probably favored the transport and spread of the pollutant magnetic materials to long distances from the road border. At site SS50 the trend of the slope instead facilitated the stagnation and concentration of pollutant magnetic mineral close to the road edge (Figure $2 \mathrm{C}$, dashed line).

At site SS87 was not possible to isolate any clear magnetic susceptibility peak (Figure 2D). At this site, located in a area of moderate traffic volume (Figure 1), 
Magnetic parameters

\begin{tabular}{|c|c|c|c|c|c|c|c|c|}
\hline \multirow{3}{*}{ Site ss 17} & \multicolumn{8}{|c|}{ inagnetic parameters } \\
\hline & $\chi$ & $\mathrm{M}_{\mathrm{rs}}$ & $\mathrm{M}_{\mathrm{s}}$ & $\mathrm{H}_{\mathrm{c}}$ & $\mathrm{H}_{\mathrm{cr}}$ & $\mathrm{H}_{\mathrm{cr}} / \mathrm{H}_{\mathrm{c}}$ & $\mathrm{M}_{\mathrm{rs}} / \mathrm{M}_{\mathrm{s}}$ & $\mathrm{M}_{\mathrm{rs}} / \chi$ \\
\hline & $10^{-8} \mathrm{~m}^{3} \mathrm{~kg}^{-1}$ & $10^{-3} \mathrm{Am}^{2} \mathrm{~kg}^{-1}$ & $10^{-3} \mathrm{~A} \mathrm{~m}^{2} \mathrm{~kg}^{-1}$ & $\mathrm{mT}$ & $\mathrm{mT}$ & & & $\mathrm{kA} \mathrm{m}^{-1}$ \\
\hline Media & 272 & 31.9 & 357.1 & 5.35 & 15.73 & 3.12 & 78 & 10.59 \\
\hline Maximum & 403 & 119.22 & 714.4 & 10.88 & 22.77 & 4.69 & 167 & 29.56 \\
\hline Minimum & 210 & 18.33 & 237.02 & 2.86 & 5.9 & 1.44 & 46 & 6.86 \\
\hline \multicolumn{9}{|l|}{ Site ss39 } \\
\hline Media & 760.57 & 61.92 & 1151.95 & 3.71 & 19.52 & 5.88 & 57 & 8.38 \\
\hline Maximum & 1047 & 97.67 & 2002 & 5.84 & 25.65 & 11.7 & 92 & 16.55 \\
\hline Minimum & 214.61 & 20.35 & 555 & 1.49 & 9.23 & 2.77 & 21 & 4.24 \\
\hline \multicolumn{9}{|l|}{ Site ss50 } \\
\hline Media & 116.5 & 12.99 & 166.51 & 4.53 & 17.31 & 4.38 & 66 & 9.34 \\
\hline Maximum & 207.11 & 50.61 & 314.5 & 11.52 & 34.54 & 7.68 & 0.16 & 28.89 \\
\hline Minimum & 44.33 & 2.07 & 30.65 & 1.5 & 5.45 & 1.94 & 21 & 3.69 \\
\hline \multicolumn{9}{|l|}{ Site ss87 } \\
\hline Media & 58.37 & 6.2 & 63.2 & 6.11 & 15.76 & 3.08 & 106 & 10.52 \\
\hline Maximum & 143.33 & 20.75 & 155.5 & 9.29 & 19.82 & 7.39 & 162 & 20.05 \\
\hline Minimum & 21.3 & 2.35 & 18.82 & 2.68 & 8.16 & 1.2 & 36 & 6.14 \\
\hline \multicolumn{9}{|l|}{ Site ss94 } \\
\hline Media & 150 & 16.99 & 123.54 & 10.8 & 32.27 & 3.01 & 0.12 & 8.17 \\
\hline Maximum & 357.53 & 55.3 & 363.28 & 12.08 & 35.62 & 3.4 & 171 & 15.47 \\
\hline Minimum & 12.75 & 0.76 & 6.63 & 9.73 & 26.48 & 2.43 & 12 & 0.8 \\
\hline
\end{tabular}

Table 1. Statistical values of magnetic parameters.

a guard rail runs close to the road side and probably acted as a primary barrier for the diffusion of the potential pollutant material.

For the sites experiencing a MS peak close to the road border (i.e., SS17, SS39, SS50, SS94), the amplitude of the observed peaks and the corresponding magnitude are variable (Figure 2A-E), the $k$ values do not decay at the same distance from the road border and lower values are reached at different distance characteristic of each site. The averaged background susceptibility value (reported as ABG in Figure 2) is highly variable across the different sites, likely mirroring the natural magnetic content of the parental rock material. Instead, the averaged peak magnetic susceptibility value (APS in Figures 2) reflects the contribution of the anthropogenic magnetic pollutants to the magnetic susceptibility peaks registered at the road border.

The lower $k$ values are recorded at site SS50, SS87, SS94, where the soil is mainly constituted by clays originating from the predominant parental rock formation (i.e., grey clay formation); the corresponding soil samples, taken off the road border, have low averaged $k$ and mass magnetic susceptibility $\left(\chi\right.$ in $\mathrm{m}^{3} / \mathrm{kg}$ ) values
(Table 1). The higher magnetic susceptibility values are recorded at SS17 and SS39; at these sites the $k$ and $\chi$ values are quite high through all the profile, although the maximum is reached at point and samples close to the road border (Figure 2A,B). The high background values observed at these sites are likely due also to the contribution of the volcanic rock exposed nearby the sampling sites (Figure 1).

The trends of $k$ along the profiles is illustrated in Figure 2 while the maximum, minimum and mean values of the specific mass susceptibility for the discrete samples at each site are listed in Table 1.

\subsection{Thermoremanent susceptibility curves}

The high-temperature thermomagnetic curves were performed on all the set of samples once obtained a magnetic extract using a Nd-Fe-B-REE (Rare Earth Element) magnet. The curves show a distinct step between $560-600^{\circ} \mathrm{C}$, that is typical of all the measured samples (Figure 3). The corresponding Curie temperature $\left(\mathrm{ca} .580^{\circ} \mathrm{C}\right)$, obtained by linear fit to inverse susceptibility [Petrovský and Kapička 2006] indicates the presence of magnetite as main magnetic carrier. An ad- 

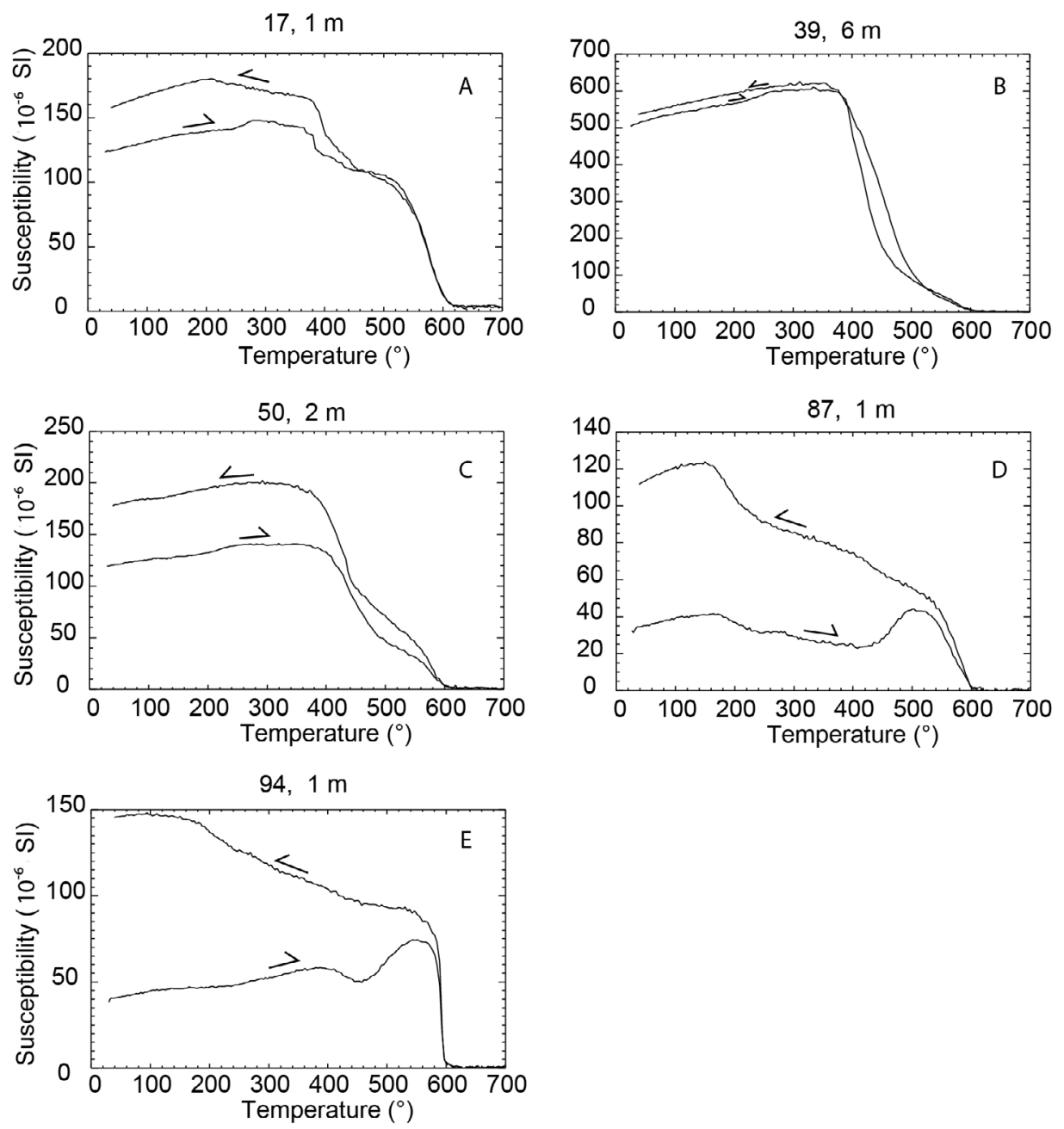

Figure 3. Thermomagnetic (A-E) curves for one representative specimen for each site.

ditional inflection at about $450^{\circ} \mathrm{C}$ is observed at samples belonging to site SS17, SS39, SS50 sites (Figure 3AC); these peaks reflects the possible presence of natural titanomagnetite [Jackson and Bowles 2014]. Quite all the thermomagnetic curves, exception made for site SS39, are not reversible; cooling curves were above the heating curves. This behavior is distinctive of the formation of new magnetic phases during heating. Newly formed magnetite may be responsible of the susceptibility peak observed over $450^{\circ} \mathrm{C}$ [Dunlop and Özdemir 1997, Zhu et al. 1999] in samples of site SS 87 and SS94 (Figure 3D,E). In general, the irreversibility of thermomagnetic curves has been already observed in several researches treating with airborne particles [Muxworthy et al. 2001, Gautam et al. 2004, Sagnotti et al. 2009] and in some cases linked to the presence of diesel exhaust samples [Sagnotti et al. 2009], whose contribution is possible in our specimens.

\subsection{Hysteresis properties}

The majority $(\sim 75 \%)$ of the soil samples show very narrow hysteresis loops and low value of coercivity $\left(1.5<\mathrm{H}_{\mathrm{c}}<6.8 \mathrm{mT}\right.$, Table 1, Figure $\left.4 \mathrm{~B}-\mathrm{H}\right)$ a behavior typically observed when magnetite is the main magnetic carrier [Roberts et al. 1995]. Slightly open curves and higher coercive force values are observed for samples SS1701, SS87, and for the whole SS94 site $\left(9.7<\mathrm{H}_{\mathrm{c}}<12 \mathrm{mT}\right.$, Figure 4I,J). Hysteresis parameters, obtained after paramagnetic slope correction, are summarized in a "Day plot" (Figure 5) [Day et al. 1977, Dunlop 2002]. Most of the data samples plot in the field of ideal PSD magnetite grains field, and their distribution parallel on the right the single domain (SD)-MD mixing curve indicating no contribution by superparamagnetic minerals (SP). Samples with higher values of $\mathrm{H}_{\mathrm{cr}} / \mathrm{H}_{\mathrm{c}}(\geq 5)$ and low $\mathrm{M}_{\mathrm{rs}} / \mathrm{M}_{\mathrm{s}}(<0.05)$ may be dominated by MD grains that are known to produce constricted hysteresis loops [Tauxe et al. 1996, Dunlop 2002]. Samples falling on the left respect to the SD-MD mixing curves may consist in a mixture of mineralogical phases.

\subsection{Room-temperature biplots}

Some compositional information of the samples can be derived from the speculation of the specific biplots of magnetic parameters [Peters and Thompson 1998, 

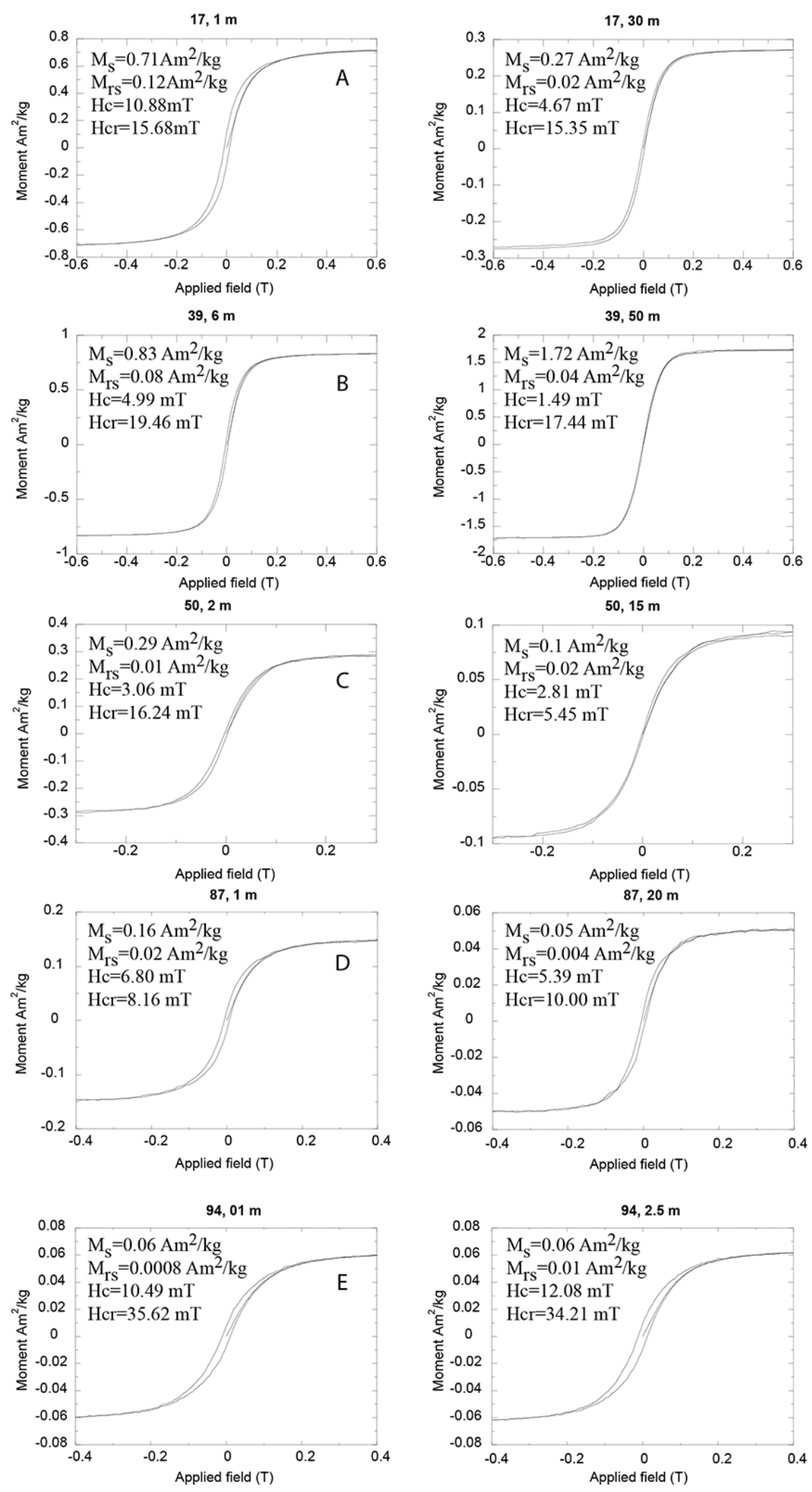

Figure 4. Representative hysteresis curves for each site (A-J). First column is relative to the samples taken nearby the road border, second column refers to the samples off the road border.

Peters and Dekkers 2003]. $\mathrm{M}_{\mathrm{rs}} / \chi$ ratio versus $\mathrm{ARM}_{40 \mathrm{mT}} / \mathrm{ARM}_{0 \mathrm{mT}}$ plot is used to identify the presence of haematite and pyrrhotites minerals, none of the sample fall in the corresponding area (Figure 6); beside that, none of the samples analyzed have a $\mathrm{H}_{\mathrm{cr}}$ greater than $40 \mathrm{mT}$, when values over $100 \mathrm{mT}$ are dis- tinctive of haematite/goethite minerals (see Table 1); instead the samples concentrate mainly in the titanomagnetite and hard magnetite field (soft magnetite lays in the lower left part of the diagram; Peters and Thompson [1998]). However, it has to be considered that the presence of paramagnetic (and or superpara- 


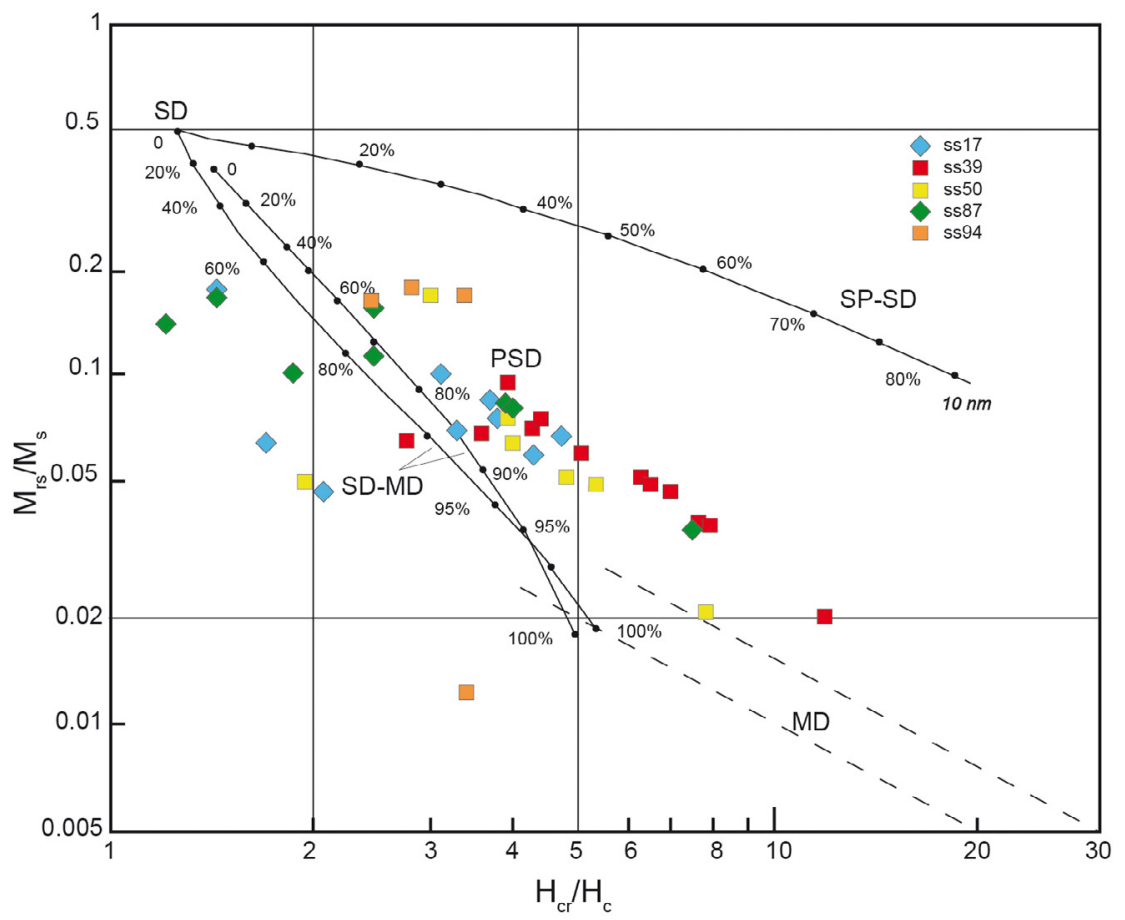

Figure 5. $\mathrm{M}_{\mathrm{rs}} / \mathrm{M}_{\mathrm{s}}$ versus $\mathrm{H}_{\mathrm{cr}} / \mathrm{H}_{\mathrm{c}}$ Day plot for the discrete soil samples. Mixing theoretical curves for magnetite with the relative volume fraction of the soft component (SP or MD) and boundaries of SD, PSD, and MD fields are reported (after Dunlop [2002]).
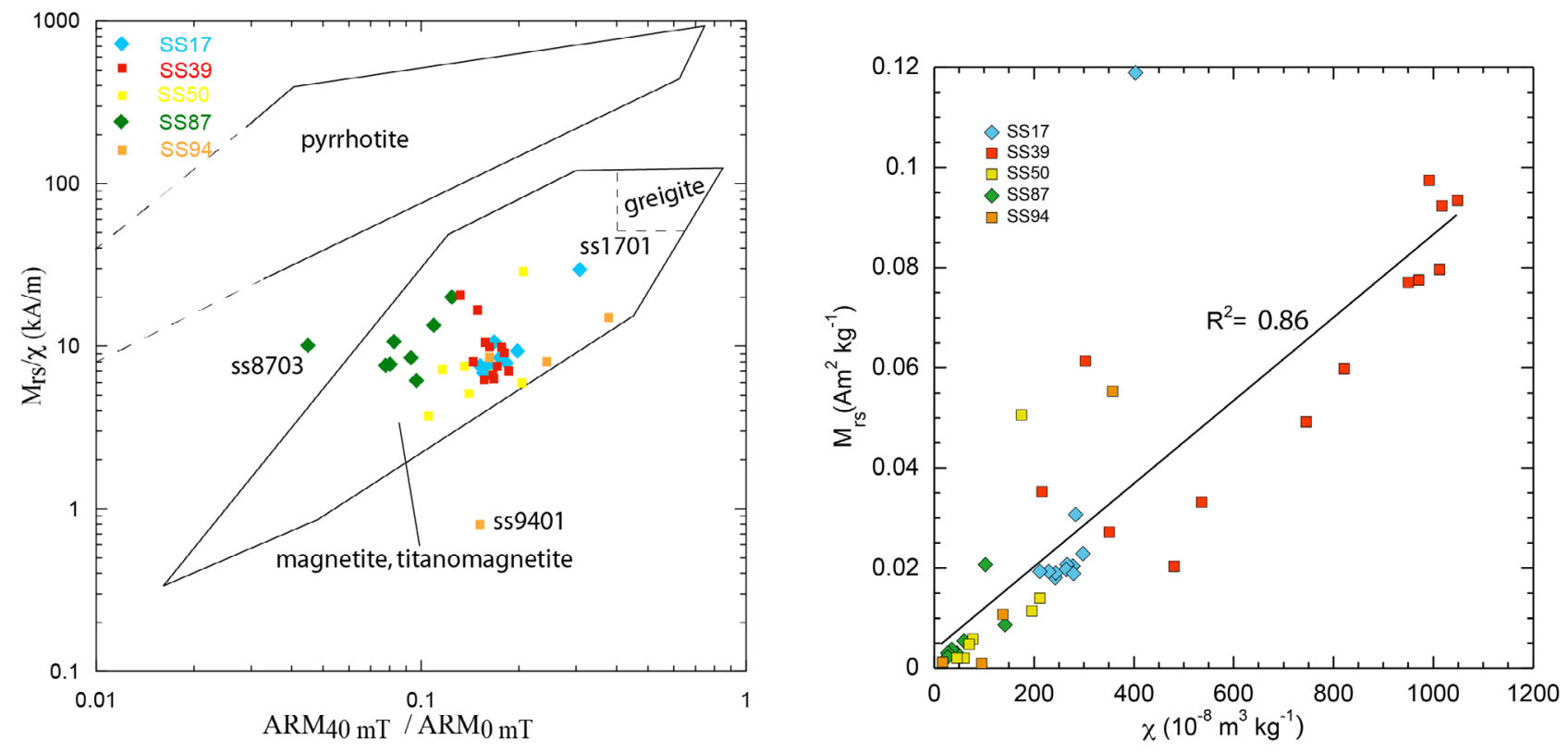

Figure 6 (left). Biplot of $\mathrm{M}_{\mathrm{rs}} / \chi$ versus $\mathrm{ARM}_{40 \mathrm{mT}} / \mathrm{ARM}_{0 \mathrm{mT}}$ (where $\mathrm{ARM}_{40 \mathrm{mT}}$ is the magnetization remaining after demagnetization at $40 \mathrm{mT}$ ). Black lines delimited the field of different magnetic phases (semi-empirical area redrawn from Peter and Thompson [1998]). Figure 7 (right). Plot for soil samples of $\mathrm{M}_{\mathrm{rs}}$ versus $\chi$ with indicated the linear regression curve. $\mathrm{R}^{2}=$ correlation coefficient.

magnetic particles, which is not our case) affecting the $\chi$ values, may contribute to lower down the $\mathrm{M}_{\mathrm{rs}} / \chi$ ratio giving unclear and not straight forward interpretation of resulting bi-plots [Thompson and Oldfield 1986, Peters and Thompson 1998].

The fairly good linear relation found for $\mathrm{M}_{\mathrm{rs}}$ and $\chi$ parameters (Figure 7; $\mathrm{R}^{2}=0.86$ ) indicates an increment in magnetic concentration for samples falling in the upper right corner of the diagram [Thompson and Old- field 1986]. Samples respecting the covariance relation have ferromagnetic minerals dominating the magnetic properties of the soils [Urbat et al. 2004]. Data displaced in the upper part of the diagram in general correspond to magnetic minerals having a significant contribution from coarse ferromagnetic grains size, originating from anthropogenic supply or specific pedogenic origin; the ferromagnetic contribution decreases toward the origin of the diagram where low $\mathrm{M}_{\mathrm{rs}}$ and $\chi$ would point 
toward paramagnetic mineral content [Lecoanet et al. 2003]. In our case study the results suggest that the variations among sites are mainly related to magnetic concentration and grain size variability, rather than differences in mineralogy [Urbat et al. 2004]. Exceptions to this behavior are found for some discrete samples falling away from the regression line (i.e., one sample of site SS17; Figure 7), for which high coercive haematite is present. The samples falling away from the origin in the graph belong to site SS39 (i.e, the ones in the right upper corner of the graph), and in particular the ones sampled close to the road border (distance less that 15 $\mathrm{m}$ ) where it is expected a major concentration of magnetic mineral of anthropogenic origin.

\subsection{FESEM and EDS analyses of Fe-particles}

Fe-rich particles of anthropogenic origin have been recognized at almost all soil samples sites when observed through the Field Emission Scanning Electron Microscope.

At sites SS39 and SS17 the magnetic material is represented prevalently by natural Fe-oxides along with fine ( $<1$ micron) sparse magnetic material of anthropogenic origin (Figure $8 \mathrm{D}$ ). Fe-oxides in lamellae shape are observed at site SS17 (Figure $8 \mathrm{C}$ ), accompanied with altered magnetic oxides of natural origin of ca. $1 \mu \mathrm{m}$ dimension. Fine Fe-oxides in aggregate form are observed at site SS50, SS87 and SS94 (Figure 8E,F,G, respectively). Fe-sulphides were detected at site SS94 (Figure $8 \mathrm{H}$ ), where they assume "orange peel" and framboid structure, the dimension varies from few micron to the nanometre. Framboid shaped sulphides of anthropogenic origin characterize the magnetic particles of the second magnetic susceptibility peak registered at site SS94 40 meter off the road border (cf. Figure 2E and Figure $8 \mathrm{H}$ ).

Other non-magnetic elements isolated in the samples and originating from anthropic contribution are: $\mathrm{Ni}$ particle, $\mathrm{Cu}$ in association with $\mathrm{Fe}$ or $\mathrm{Zn}$, these latter probably deriving from agricultural fungicide (probably at site SS39) and to traffic derived emission [Chaparro et al. 2010]; $\mathrm{Cu}$ can be originated from brakes abraded particles and $\mathrm{Zn}$ from tire abrasion. Instead the $\mathrm{Pb}$ found is likely a residual of the circulation of "pre-euro" engines (site SS94 and SS87).

\section{Discussions and conclusion}

Via Salaria is one of the main interregional roads, connecting the city of Rome to the north-eastern districts, it is characterized by variable automotive and truck traffic flow (Figure 1). The ensemble of the analyses done shows that at three sites, i.e., SS17, SS50 and SS94, the increase of the $k$ mean values close to the road border $(<5 \mathrm{~m})$ is frankly due to anthropogenic polluting contribution. At two of these sites the natural ferromagnetic concentration is quite low (Table 1 ) and the paramagnetic contribution is significant, the resulting $k$ peak clearly identifies better the presence of magnetic anthropogenic materials (e.g., SS50 and SS94). For these sites the morphological analysis evidenced the presence of Fe-oxides aggregates and orange peel titanomagnetite of anthropogenic origin. Instead, at other sites the anthropic contribution (e.g., spherical anthropogenic magnetite associated to nickel and sulphates), is partially obscured by the natural magnetic content of the parent rock material, making difficult to define the limit of the spatial distribution of the magnetic pollutants. This is particularly true for site SS39 and SS17 where the soil in enriched by natural titanomagnetite. A fairly good correlation exists between the remanent magnetization and $\chi\left(10^{-8} \mathrm{~m}^{3} \mathrm{~kg}^{-1}\right)$ that points to higher concentration of ferromagnetic minerals for these two sites for which the contribution from the rock parent materials plays a fundamental role (i.e., natural titanomagnetite of volcanic origin).

The magnetic analyses pointed mainly toward PSD magnetite grains component as characteristic of the magnetic carriers, and/ or a mixing of SD-MD magnetite and titanomagnetite with minor or no contribution by SP grains. Haematite was found only at one soil sample (at site SS17, sample at $1 \mathrm{~m}$ off road border), and it is likely of anthropogenic origin.

Some features were noticed to influence significantly the transport and diffusion of the magnetic material from automotive origin, as: (i) guardrails (e.g., site SS87) preventing the diffusion of the majority of pollutant material into the survey area; (ii) slope, conditioning that can widen the diffusion of pollutant over an area, or concentrate it (SS39 and SS50, respectively); (iii) ditches along roads, creating a shadowing zone for the pollutant diffusions (SS17 and SS94).

As a general remark the averaged susceptibility values decrease away from the city of Rome, reflecting in part the characters of the rock parental material, and the contribution from automotive circulation to the magnetic fraction. This specific aspect is visible in Figure 9, where the averaged magnetic susceptibility $\chi\left(10^{-8} \mathrm{~m}^{3} \mathrm{~kg}^{-1}\right)$ and SIRM values (Figure $\left.8 \mathrm{~A}, \mathrm{~B}\right)$ decreases away from the road side border for sites SS17, SS39, SS50 (characterized by high and medium traffic volume) and show low averaged values at sites SS87 and SS94 (area of low traffic volume). At site SS39 the ratio $\mathrm{SIRM} / \chi$ (Figure 9 ), increases slightly at increasing distance from the road side border, suggesting a decrease in concentration and/or in grain size of magnetic minerals away from the road [Moreno et al. 2003]. 

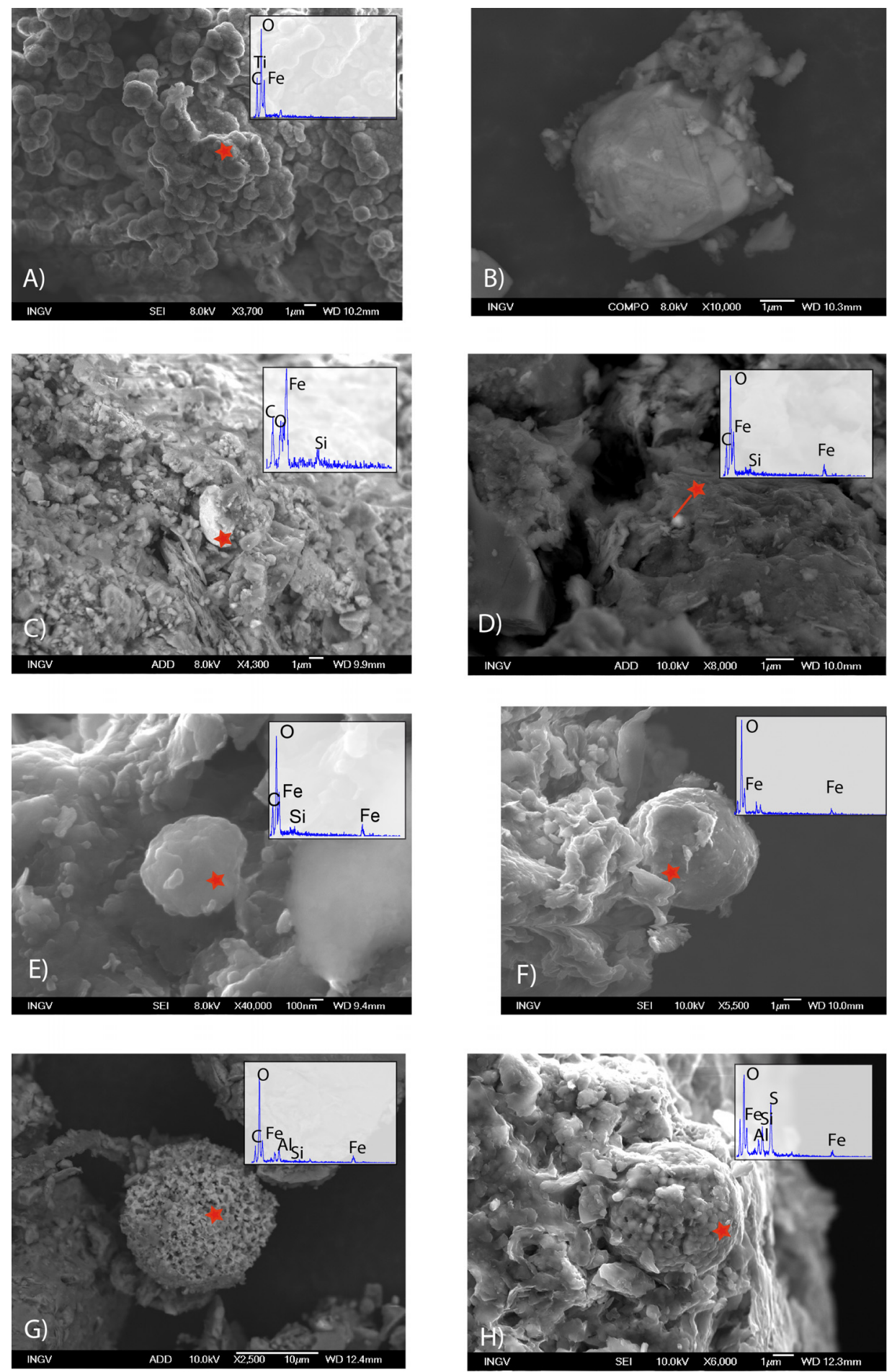

Figure 8. Morphological analysis and chemical composition of selected sample. (A) Road dusts Fe-Oxides aggregates as comparison (personal communication L. Alfonsi); (B) natural Ti-reach magnetite, in the images SS17 sample; (C) lamellae shaped Fe-oxides, sample SS17-1; (D) Nanometre Fe-Oxides spherule from SS39-5; (E) orange peel shaped Fe-oxides at sample SS50-2; (F) orange peel Fe-oxides sample SS874; (G) Fe-Oxides aggregates, SS94-5; (H) framboid shaped sulphide, SS94-40. The numbers aside the site abbreviation indicate the distance from the road border; red stars indicate the position of chemical composition analysis.

To conclude, this study confirms that the in situ magnetic susceptibility measurements on soils sediments is a valuable method to rapidly identify alteration into the magnetic susceptibility profile, due to natural or anthropogenic elements. Nevertheless, in order to give a final statement on the nature of the magnetic materials, this low cost and rapid survey needs to be associ- ated with detailed rock-magnetic laboratory analyses and to microscope observations and analyses. Higher susceptibility values related to the presence of anthropogenic pollutants have been recorded in a number of the investigated sites, their major impact is evident within the first $5 \mathrm{~m}$ from the road side.

This study showed how natural soils, even if there 

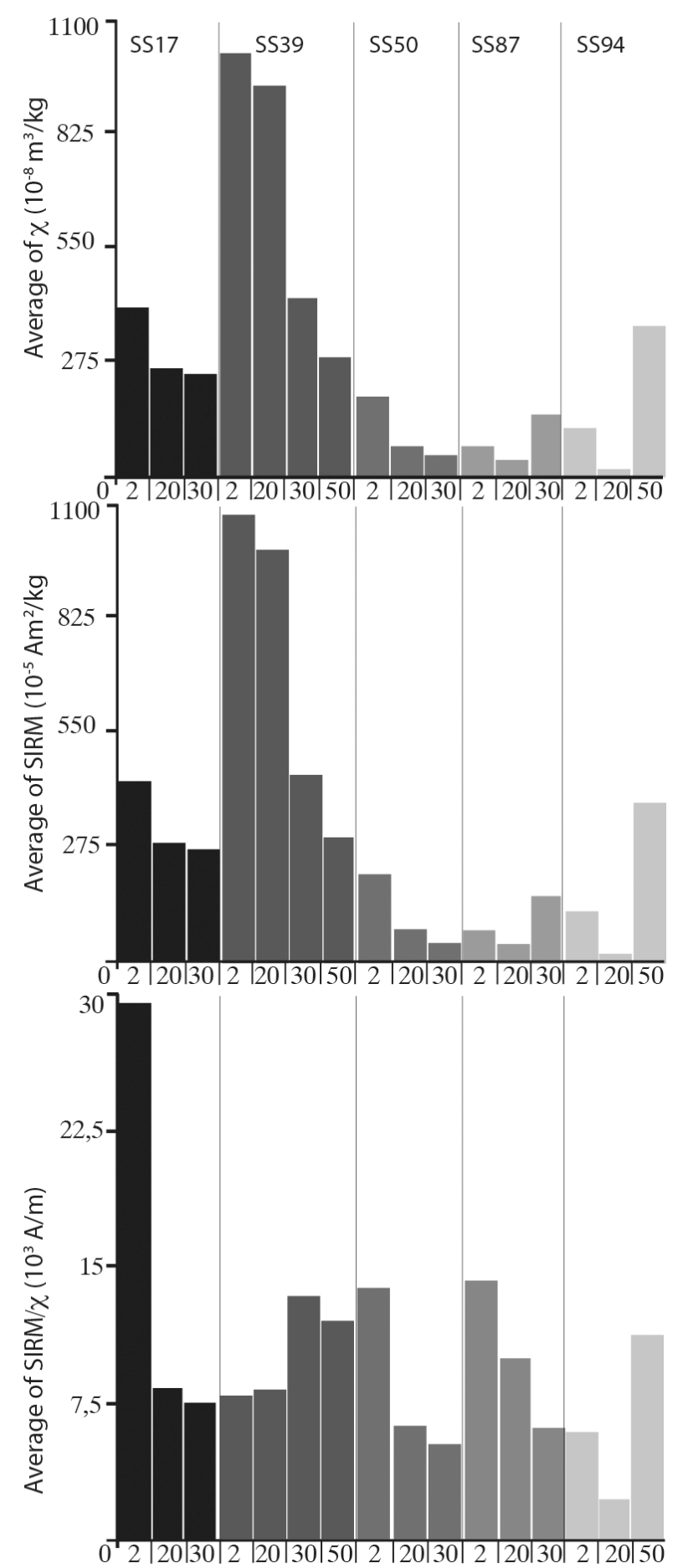

Figure 9. Values of susceptibility, SIRM and SIRM $/ \chi$ with respect of the distance from the road border, and traffic volume (decreasing from black to light grey).

are uneven conditions of rock parental material, geomorphology and local site conditions, can be used as screening indicators for the enhancement in magnetic minerals concentration, due to pollution derived from vehicle emissions. Furthermore, as showed by other magnetic methods applied to monitoring air pollution in Rome [Moreno et al. 2003], these kind of studies can provide a long term record of the magnetic pollution load to a natural or urban environment.
Acknowledgements. We are grateful to Leonardo Sagnotti and Aldo Winkler for their fruitful suggestions and advices. The readiness and clarity of the work was ameliorated thanks to the advices and corrections of the reviewers (i.e., M. Chaparro and H. Santovaia). The work has been carried out utilizing the instruments and facilities available at the INGV laboratory of paleomagnetism in Rome.

\section{References}

Blaha, P.U., and E . Appel (2005). Magnetic susceptibility of dust- loaded leaves as a proxy of traffic-related heavy metal pollution in Kathmandu city, Nepal, Atmos. Environ., 39, 2201-2211.

Bućko, M.S., T. Magiera, B. Johansond, E. Petrovský and L.J. Pesonen (2011). Identification of magnetic particulates in road dust accumulated on roadside snow using magnetic, geochemical and micro-morphological analyses, Environ. Pollut., 5, 1266-1276.

Carta Geologica d'Italia 1:100,000, Sheets 150, 144, and 139, available at: http:/ / www.isprambiente.gov.it/ it/ cartografia / carte-geologiche-e-geotematiche/ carta-geologica-alla-scala-1-a-100000.

Chaparro, M.A.E., D.C. Marié, C.S.G. Gogorza, A. Navas, and A.M. Sinito (2010). Magnetic studies and scanning electron microscopy-X-ray energy dispersive spectroscopy analyses of road sediments, soils and vehicle-derived emissions, Stud. Geophys. Geod., 54, 633-650.

Day, R., M. Fuller and V. Schmidt (1997). Hysteresis properties of titanomagnetites: grain-size and compositional dependence, Phys. Earth Planet. Inter., 13, 260-267.

D’Emilio, M., D. Chianese, R. Coppola, M. Macchiato and M. Ragosta (2007). Magnetic susceptibility measurements as proxy method to monitor soil pollution: development of experimental protocols for field surveys, Environ. Monit. Assess., 125, 137-146.

Dunlop, D.J., and Ö. Özdemir (1997). Rock magnetism: fundamentals and frontiers. Cambridge University Press, Cambridge.

Dunlop, D.J. (2002). Theory and application of the Day plot $\left(\mathrm{M}_{\mathrm{rs}} / \mathrm{M}_{\mathrm{s}}\right.$ versus $\left.\mathrm{H}_{\mathrm{cr}} / \mathrm{H}_{\mathrm{c}}\right)$ 1. Theoretical curves and tests using titanomagnetite data, J. Geophys. Res., 107, 1-22.

Durza, D. (1999). Heavy metals contamination and magnetic susceptibility in soils around metallurgical plant, Phys. Chem. Earth, 24, 541-543.

Gautam, P., U. Blaha, E. Appel and G. Neupane (2004). Environmental magnetic approach towards the quantification of pollution in Kathmandu urban area, Nepal, Phys. Chem. Earth, 29, 973-984.

Goddu, S.R., E. Appel, D. Jordanova and R. Wehland (2004). Magnetic properties of road dust from Visakhapatnam (India) - relationship to industrial pollution and road traffic, Phys. Chem. Earth, 29, 985-995. 
Jackson, M.J., and J. Bowles (2014). Curie temperatures of titanomagnetite in ignimbrites: Effects of emplacement temperatures, cooling rates, exsolution, and cation ordering, Geochem. Geophy. Geosy., 15 (11), 4343-4368.

Hanesch, M., and R. Scholger (2002). Mapping of heavy metal loadings in soils by means of magnetic susceptibility measurements, Environ. Geol., 42, 857870.

Hoffmann, V., M. Knab and E. Appel (1999). Magnetic susceptibility mapping of roadside pollution, J. Geochem. Explor., 66, 313-326.

Kapička, A., N. Jordanova, E. Petrovský and S. Ustjak (2001). Effect of different soil conditions on magnetic parameters of power-plant fly ashes, J. Appl. Geophys., 48, 93-102.

Kim, W., S.J. Doh and Y. Yu (2009). Anthropogenic contribution of magnetic particulates in urban roadside dust, Atmos. Environ., 43, 3137-3144.

Lecoanet, H., F. Leveque and J.P. Ambrosi (2003). Combination of magnetic parameters: an efficient way to discriminate soil contamination sources (south France), Environ. Pollut., 122, 229-234.

Lu, S.G., H.Y. Wang and J.L. Guo (2011). Magnetic enhancement of urban roadside soils as a proxy of degree of pollution by traffic-related activities, Environ. Earth Sci., 64, 359-371.

Magiera, T., Z. Strzyszcz, A. Kapička and E. Petrovský (2006). Discrimination of lithogenic and anthropogenic influences on topsoil magnetic susceptibility in Central Europe, Geoderma, 130, 299-311.

Maher, B.A., C. Moore and J. Matzka (2008). Spatial variation in vehicle-derived metal pollution identified by magnetic and elemental analysis of roadside tree leaves, Atmos. Environ., 42, 364-373.

Marié, D.C., M.A.E. Chaparro, C.S.G. Gogorza, A. Navas and A.M. Sinito (2010). Vehicle-derived emissions and pollution on the road Autovia 2 investigated by rock-magnetic parameters: a case of study from Argentina, Stud. Geophys. Geod., 54, 135-152.

Moreno, E., L. Sagnotti, J. Dinares-Turell , A.E. Legzdins and A. Cascella (2003). Biomonitoring of traffic air pollution in Rome using magnetic properties of tree leaves, Atmos. Environ., 37, 2967-2977.

Muxworthy, A.R., J. Matzka and N. Petersen (2001). Comparison of magnetic parameters of urban atmospheric particulate matter with pollution and meteorological data, Atmos. Environ., 35, 4379-4386.

Peters, C., and R. Thompson (1998). Magnetic identification of selected natural iron oxides and sulphides, J. Magn. Magn. Mater., 183, 365-374.

Peters, C., and M.J. Dekkers (2003). Selected room temperature magnetic parameters as a function of min- eralogy, concentration and grain size, Phys. Chem. Earth, 28, 659-667.

Petrovský, E., A. Kapička, N. Jordanova and L. Boruvka (2001). Magnetic properties of alluvial soils contaminated with lead, zinc and cadmium, J. Appl. Geophys., 48, 127-136.

Petrovský, E. and A. Kapička (2006). On determination of the Curie point from thermomagnetic curves, J. Geophys. Res., 111, B12S27; doi:10.1029/2006JB004 507.

Roberts, A.P., Y. Cui and K.L. Verosub (1995). Waspwaisted hysteresis loops: Mineral magnetic characteristics and discrimination of components in mixed magnetic system, J. Geophys. Res., 100, 17909-17924.

Sagnotti, L., J. Taddeucci, A. Winkler and A. Cavallo (2009). Compositional, morphological, and hysteresis characterization of magnetic airborne particulate matter in Rome, Italy, Geochem. Geophy. Geosy., 10 (8); doi:10.1029/2009GC002563.

Strzyszcz, Z., and T. Magiera (1998). Magnetic susceptibility and heavy metals contamination in soils of southern Poland, Phys. Chem. Earth, 23, 1127-1131.

Szönyi, M., L. Sagnotti and A.M. Hirt (2008). A refined biomonitoring study of airborne particulate matter pollution in Rome, with magnetic measurements on Quercus Ilex tree leaves, Geophys. J. Int., 173, 127141.

Tauxe, L., T.A.T. Mullender and T. Pick (1996). Potbellies, wasp-waists and superparamagnetism in magnetic hysteresis, J. Geophys. Res., 101, 571-583.

Thompson, R., and F. Oldfield (1986). Environmental Magnetism, Allen \& Unwin, London.

Urbat, M., E. Lehndorff and L. Schwark (2004) Biomonitoring of air quality in the Cologne conurbation using pine needles as a passive sampler - Part I: magnetic properties, Atmos. Environ., 38, 3781-3792.

Xia, D.S., F.H. Chen, J. Bloemendalc, X.M. Liu, Y. Yu and L.P. Yang (2008). Magnetic properties of urban dustfall in Lanzhou, China, and its environmental implications, Atmos. Environ., 42, 2198-2207.

Zhu, R.X., Y.X. Pan and Q.S. Liu (1999). Geomagnetic excursions recorded in Chinese loess in the last 70,000 years, Geophys. Res. Lett., 26, 505-508.

\footnotetext{
${ }^{\star}$ Corresponding author: Laura Alfonsi, Istituto Nazionale di Geofisica e Vulcanologia, Rome, Italy; email: laura.alfonsi@ingv.it.
}

(C) 2016 by the Istituto Nazionale di Geofisica e Vulcanologia. All rights reserved. 